\title{
Right ventricular dysfunction affects survival after surgical left ventricular restoration
}

\author{
Lotte E. Couperus, MD, ${ }^{\mathrm{a}}$ Victoria Delgado, $\mathrm{MD}, \mathrm{PhD},{ }^{\mathrm{a}}$ Meindert Palmen, $\mathrm{MD}, \mathrm{PhD},{ }^{\mathrm{b}}$ \\ Marieke E. van Vessem, MD, ${ }^{\mathrm{a}, \mathrm{b}}$ Jerry Braun, MD, PhD, ${ }^{\mathrm{b}}$ Marta Fiocco, PhD, ${ }^{\mathrm{c}, \mathrm{d}}$ Laurens F. Tops, MD, PhD, ${ }^{\mathrm{a}}$ \\ Harriëtte F. Verwey, MD, PhD, ${ }^{a}$ Robert J. M. Klautz, MD, PhD, ${ }^{b}$ Martin J. Schalij, MD, PhD, and \\ Saskia L. M. A. Beeres, MD, PhD ${ }^{\mathrm{a}}$
}

\begin{abstract}
Objective: Several clinical and left ventricular parameters have been associated with prognosis after surgical left ventricular restoration in patients with ischemic heart failure. The aim of this study was to determine the prognostic value of right ventricular function.
\end{abstract}

Methods: A total of 139 patients with ischemic heart failure (62 \pm 10 years; $79 \%$ were male; left ventricular ejection fraction $27 \% \pm 7 \%$ ) underwent surgical left ventricular restoration. Biventricular function was assessed with echocardiography before surgery. The independent association between all-cause mortality and right ventricular fractional area change, tricuspid annular plane systolic excursion, and right ventricular longitudinal peak systolic strain was assessed. The additive effect of multiple impaired right ventricular parameters on mortality also was assessed.

Results: Baseline right ventricular fractional area change was $42 \% \pm 9 \%$, tricuspid annular plane systolic excursion was $18 \pm 3 \mathrm{~mm}$, and right ventricular longitudinal peak systolic strain was $-24 \% \pm 7 \%$. Within 30 days after surgery, 15 patients died. Right ventricular fractional area change (hazard ratio, $0.93 ; 95 \%$ confidence interval, $0.88-0.98 ; P<.01)$, tricuspid annular plane systolic excursion (hazard ratio, $0.80 ; 95 \%$ confidence interval, $0.66-0.96 ; P=.02$ ), and right ventricular longitudinal peak systolic strain (hazard ratio, 1.15 ; $95 \%$ confidence interval, $1.05-1.26 ; P<.01)$ were independently associated with 30-day mortality, after adjusting for left ventricular ejection fraction and aortic crossclamping time. Right ventricular function was impaired in $21 \%, 20 \%$, and $27 \%$ of patients on the basis of right ventricular fractional area change, tricuspid annular plane systolic excursion, and right ventricular longitudinal peak systolic strain, respectively. Any echocardiographic parameter of right ventricular dysfunction was present in 39\% of patients. The coexistence of several impaired right ventricular parameters per patient was independently associated with increased 30-day mortality (hazard ratio, 2.83; 95\% confidence interval, 1.64$4.87, P<.01$ per additional impaired parameter).

Conclusions: Baseline right ventricular systolic dysfunction is independently associated with increased mortality in patients with ischemic heart failure undergoing surgical left ventricular restoration. (J Thorac Cardiovasc Surg 2017;153:845-52)

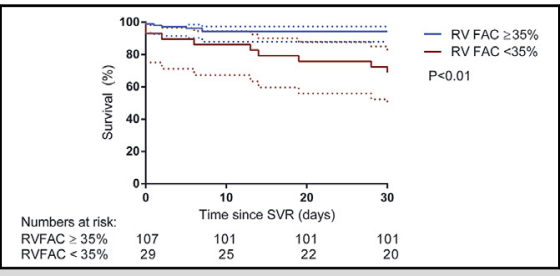

Survival curves for baseline normal versus impaired RVFAC in patients after SVR

\section{Central Message}

Baseline RV systolic dysfunction is independently associated with increased mortality in patients with ischemic heart failure undergoing surgical ventricular restoration.

\section{Perspective}

$\mathrm{RV}$ dysfunction is frequent in patients with heart failure undergoing surgical ventricular restoration and is independently associated with increased 30-day mortality. The coexistence of multiple impaired RV parameters further increases mortality. Perioperative measures for RV protection or refraining from surgery should be carefully considered in surgical candidates with RV dysfunction.

See Editorial Commentary page 853.

See Editorial page 843 .
Surgical ventricular restoration (SVR) of the left ventricle (LV) in addition to coronary revascularization yields a survival benefit compared with revascularization alone if the

\footnotetext{
From the ${ }^{\mathrm{a}}$ Department of Cardiology, Leiden University Medical Centre, Leiden, The Netherlands; ${ }^{b}$ Department of Cardiothoracic Surgery, Leiden University Medical Centre, Leiden, The Netherlands; ${ }^{c}$ Department of Medical Statistics and Bioinformatics, Leiden University Medical Centre, Leiden, The Netherlands; and ${ }^{\mathrm{d}}$ Mathematical Institute, Leiden University, Leiden, The Netherlands.

Received for publication Feb 12, 2016; revisions received July 10, 2016; accepted for publication Sept 8, 2016; available ahead of print Oct 14, 2016.
}

predicted postoperative LV end-systolic volume index is $70 \mathrm{~mL} / \mathrm{m}^{2}$ or less. This is the outcome of a substudy of the Surgical Treatment for Ischemic Heart Failure trial in which

\footnotetext{
Address for reprints: Saskia L. M. A. Beeres, MD, PhD, Department of Cardiology, Leiden University Medical Center, PO Box 9600, 2300 RC Leiden, The Netherlands (E-mail: s.1.m.a.beeres@lumc.nl). $0022-5223 / \$ 36.00$

Copyright (c) 2016 by The American Association for Thoracic Surgery http://dx.doi.org/10.1016/j.jtcvs.2016.09.038
} 


$\begin{aligned} & \text { Abbreviations and Acronyms } \\ & \text { CABG }=\text { coronary artery bypass grafting } \\ & \text { CI }=\text { confidence interval } \\ & \text { HR }=\text { hazard ratio } \\ & \text { LV }=\text { left ventricular } \\ & \text { LVAD }=\text { left ventricular assist device } \\ & \text { LVEF }=\text { left ventricular ejection fraction } \\ & \text { NYHA }=\text { New York Heart Association } \\ & \text { RV }=\text { right ventricular } \\ & \text { RVFAC }=\text { right ventricular fractional area change } \\ & \text { RV LPSS }=\text { right ventricular longitudinal peak } \\ & \text { systolic strain } \\ & \text { SVR }=\text { surgical ventricular restoration } \\ & \text { TAPSE }=\text { tricuspid annular plane systolic } \\ & \text { excursion }\end{aligned}$

Scanning this QR code will take you to a video for the article.

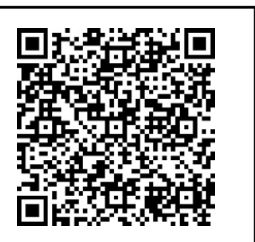

1000 patients with ischemic heart failure and anterior akinesia or dyskinesia were randomized to coronary artery bypass grafting (CABG) surgery alone or combined with SVR. ${ }^{1}$ Other factors that may affect outcome in patients undergoing SVR include poor LV function, high preoperative LV endsystolic volume index, and New York Heart Association (NYHA) functional class IV. ${ }^{2-4}$ So far, only limited data are available on the influence of right ventricular (RV) function and dimensions on outcome after SVR. ${ }^{5,6}$ The reduction in LV volume after SVR may lead to increased LV filling pressures and increased afterload of the right ventricle that may decrease its function. Furthermore, the improvement in LV systolic function after SVR may lead to increased preload of the right ventricle. Preoperative impaired RV systolic function may have a negative impact on outcome after SVR, because the right ventricle may not be able to handle the increased preload and afterload. Therefore, preoperative RV systolic function might be an important variable to consider in the selection of patients with ischemic heart failure who may be candidates for SVR. The purpose of the present study was to assess whether RV function is associated with postoperative survival in patients with heart failure undergoing SVR.

\section{MATERIALS AND METHODS \\ Study Population and Protocol}

The study population comprised 143 consecutive patients who underwent SVR according to the technique described by Dor between January 2006 and January 2014. ${ }^{7}$ All patients had symptomatic heart failure despite optimal medication and a postinfarction LV aneurysm. The decision to perform SVR was made by the institutional multidisciplinary heart team. Exclusion criteria for the current study were incomplete follow-up $(\mathrm{N}=2)$ and insufficient preoperative transthoracic echocardiographic image quality for the current analysis $(\mathrm{N}=2)$. According to the institutional protocol, all patients underwent clinical and echocardiographic evaluation before SVR. Clinical data, including demographic characteristics, medical history, comorbidities, and functional status according to the NYHA classification, were prospectively collected in the departmental cardiology information system (EPD-Vision, Leiden University Medical Center, Leiden, The Netherlands) and retrospectively analyzed. Creatinine clearance was estimated using the Cockcroft-Gault formula. ${ }^{8}$ All-cause mortality was registered during 30 days of follow-up through case record review and the national death registry. The study was conducted in accordance with the Declaration of Helsinki. The institutional ethical committee approved this retrospective evaluation of clinically acquired data.

\section{Transthoracic Echocardiography}

In line with the institutional protocol, routine transthoracic echocardiography was performed before SVR. Images were obtained with the patient in the left lateral decubitus and supine position with a commercially available system (Vivid 7 or E9; General Electric-Vingmed, Horten, Norway) and digitally stored in cine-loop format. For the present study, measurements were performed by a cardiologist specialized in echocardiography using commercially available software (EchoPAC version 112.0.1; General Electric-Vingmed Ultrasound AS). For the assessment of LV systolic function, LV end-systolic and end-diastolic volumes were measured from the apical 4- and 2-chamber views, and LV ejection fraction (LVEF) was calculated using the Simpson's biplane technique. ${ }^{9}$ LV end-systolic volume was indexed for body surface area to obtain LV end-systolic volume index. End-diastolic left atrial volume was measured in the apical 4- and 2-chamber views and indexed for body surface area to obtain left atrial volume index. ${ }^{9}$ Peak early diastolic mitral inflow velocity was measured on pulsed-wave Doppler recordings, and septal and lateral early diastolic mitral annulus velocities were measured on tissue Doppler imaging of the apical 4-chamber view. Peak early diastolic mitral inflow velocity was divided by the average of septal and lateral annular velocities to acquire the peak early diastolic mitral inflow velocity/early diastolic mitral annulus velocity ratio. ${ }^{10}$ For comprehensive RV functional assessment, RV end-systolic and enddiastolic areas were traced in the RV apical view to calculate fractional area change (right ventricular fractional area change [RVFAC]). Tricuspid annular plane systolic excursion (TAPSE) was calculated on M-mode recordings of the lateral tricuspid annulus in the RV apical view. Furthermore, speckle-tracking echocardiography of the RV free wall was performed. RV longitudinal peak systolic strain (RV LPSS) was measured in the basal, midventricular, and apical segments of the RV free wall, and global RV LPSS was calculated as the average of the 3 measurements. Cutoff values for impaired RV functional parameters were derived from the most recent American Society of Echocardiography recommendations for cardiac chamber quantification, and assessment of the right heart was assessed by echocardiography in adults and defined as RVFAC less than 35\%, TAPSE less than $16 \mathrm{~mm}$, and RV LPSS greater than $-20 \%$. $^{9,11}$ The diameter of the tricuspid valve annulus was measured during diastole on the apical RV view. ${ }^{12}$ The maximum tricuspid regurgitant jet gradient was measured from continuous-wave Doppler using the modified Bernoulli equation. ${ }^{11}$ Right atrial pressure was estimated as 3,8, or $15 \mathrm{~mm} \mathrm{Hg}$ on the basis of the diameter and inspiratory collapse of the inferior caval vein in the subcostal view. ${ }^{9}$ Systolic pulmonary arterial pressure was calculated by summation of the tricuspid regurgitant jet gradient and right atrial pressure. Pulmonary hypertension was defined as systolic pulmonary arterial pressure greater than $50 \mathrm{~mm} \mathrm{Hg}{ }^{13}$

\section{Surgical Left Ventricular Restoration}

The details of the SVR procedure according to Dor have been described. $^{7,14}$ All operations were performed using cardiopulmonary 
TABLE 1. Baseline characteristics and hazards ratios for univariable Cox regression analysis of 30-day mortality

\begin{tabular}{|c|c|c|c|c|}
\hline & \multirow[b]{2}{*}{$\mathbf{N}=139$} & \multicolumn{3}{|c|}{ 30-d mortality } \\
\hline & & HR & $95 \% \mathrm{CI}$ & $P$ value \\
\hline \multicolumn{5}{|l|}{ Clinical and surgical characteristics } \\
\hline Age at operation $(y)$ & $62 \pm 10$ & 1.02 & $0.97-1.08$ & .50 \\
\hline Male sex $(\%)$ & 79 & 1.77 & $0.40-7.83$ & .45 \\
\hline NYHA functional class 3 or 4 & 55 & 3.38 & $0.95-11.97$ & .06 \\
\hline Creatinine clearance $(\mathrm{mL} / \mathrm{min})$ & $79 \pm 28$ & 1.00 & $0.98-1.02$ & .92 \\
\hline euroSCORE II ( $\%)$ & 5 (IQR, 3-12) & 1.05 & $1.02-1.08$ & $<.01$ \\
\hline Previous sternotomy $(\%)$ & 12 & 1.90 & $0.54-6.73$ & .32 \\
\hline Nonelective surgery $(\%)$ & 21 & 4.68 & $1.69-12.90$ & $<.01$ \\
\hline Aortic crossclamping time (min) & $148 \pm 69$ & 1.01 & $1.00-1.01$ & $<.01$ \\
\hline Concomitant procedures $(\%)$ & 90 & 23.83 & $0.02-32344.19$ & .39 \\
\hline CABG $(\%)$ & 53 & 3.81 & $1.07-13.50$ & .04 \\
\hline MV surgery $(\%)$ & 53 & 1.86 & $0.63-5.43$ & .26 \\
\hline TV surgery $(\%)$ & 26 & 1.40 & $0.48-4.10$ & .54 \\
\hline VT ablation $(\%)$ & 42 & 0.70 & $0.24-2.04$ & .51 \\
\hline \multicolumn{5}{|l|}{ Echocardiographic characteristics } \\
\hline $\operatorname{LVEF}(\%)$ & $27 \pm 7$ & 0.93 & $0.87-0.99$ & .03 \\
\hline $\operatorname{LVESVI}\left(\mathrm{mL} / \mathrm{m}^{2}\right)$ & $87 \pm 41$ & 1.00 & $0.99-1.01$ & .64 \\
\hline LAVI $\left(\mathrm{mL} / \mathrm{m}^{2}\right)$ & $46 \pm 18$ & 1.02 & $0.99-1.04$ & .23 \\
\hline $\mathrm{E} / \mathrm{E}^{\prime}$ ratio & $18 \pm 9$ & 1.02 & $0.96-1.08$ & .55 \\
\hline RVFAC $(\%)$ & $42 \pm 9$ & 0.92 & $0.88-0.97$ & $<.01$ \\
\hline TAPSE $(\mathrm{mm})$ & $18 \pm 3$ & 0.78 & $0.65-0.94$ & $<.01$ \\
\hline RV LPSS ( $\%)$ & $-24 \pm 7$ & 1.14 & $1.04-1.24$ & $<.01$ \\
\hline TV annulus (mm) & $32 \pm 6$ & 1.08 & $0.99-1.17$ & .07 \\
\hline TR grade $\geq 2(\%)$ & 19 & 1.56 & $0.50-4.89$ & .45 \\
\hline Pulmonary hypertension & 12 & 1.89 & $0.53-6.70$ & .32 \\
\hline
\end{tabular}

Bold signifies statistical significance. HR, Hazard ratio; CI, confidence interval; NYHA, New York Heart Association; euroSCORE, European System for Cardiac Operative Risk Evaluation; $I Q R$, interquartile range; $C A B G$, coronary artery bypass grafting; $M V$, mitral valve; $T V$, tricuspid valve; $V T$, ventricular tachycardia; $L V E F$, left ventricular ejection fraction; LVESVI, left ventricular end-systolic volume index; $L A V I$, left atrial volume index; $E / E^{\prime}$, peak early diastolic mitral inflow velocity/early diastolic mitral annulus velocity; RVFAC, right ventricular fractional area change; TAPSE, tricuspid annular plane systolic excursion; RV LPSS, right ventricular longitudinal peak systolic strain; TR, tricuspid regurgitation.

bypass, aortic crossclamping, and intermittent warm blood cardioplegia. In summary, the LV was opened through the infarcted area and a Fontan stitch was placed at the transitional zone between viable and scarred myocardium. A mannequin balloon (TRISVR, Chase Medical, Richardson, Tex) was used to determine both the new size and the shape of the residual LV cavity. For size, the balloon was filled at $55 \mathrm{~mL} / \mathrm{m}^{2}$ body surface area. The balloon also allowed proper orientation of the neo-apex and the patch used to close the defect, which was sutured in a way directed obliquely at the aortic outflow tract to ensure an elliptical shape and avoid a boxlike or spherical shape. Concomitant procedures were performed when indicated. Nonelective surgery was defined as surgery performed during an urgent admission.

\section{Statistical Analysis}

Continuous variables are expressed as mean \pm standard deviation when normally distributed or otherwise as median and interquartile range. Categoric data are presented as frequencies and percentages. Univariable Cox regression analysis was performed to assess the association between 30day mortality and baseline clinical, surgical, and echocardiographic parameters by estimating the hazard ratio (HR) and $95 \%$ confidence interval (CI). Kaplan-Meier survival curves and $95 \%$ CI for patients with normal versus impaired echocardiographic indices of RV function were estimated. Significant variables in the univariable analysis were entered in several nonnested multivariable analyses. Regression analysis was performed on 15 events, and 1 variable was entered for every 5 events in the multivariable analysis. LVEF and aortic crossclamping time were considered the clinically most relevant variables and were included in the multivariable analysis along with $1 \mathrm{RV}$ parameter per model. Furthermore, patients were classified as having no, 1, 2, or 3 impaired RV parameters. The association between the number of impaired RV parameters and mortality was assessed using Cox proportional hazard regression models. To define the intraobserver and interobserver variability, measurements for RV functional parameters were repeated for 20 randomly selected patients by the same observer and a second independent observer, both unaware of clinical outcome. Intraobserver and interobserver variability were assessed using Bland-Altman analysis and are expressed as mean difference \pm standard deviation. Statistical analysis was performed by using SPSS for Windows (version 23.0, Armonk, NY).

\section{RESULTS \\ Baseline Clinical and Echocardiographic Data}

In total, 139 patients with heart failure (mean age, $62 \pm 10$ years; $79 \%$ were male) were included. Table 1 summarizes baseline clinical and echocardiographic data. Baseline NYHA functional class was 3 or 4 in 77 patients $(55 \%)$, and mean LVEF was 27\% $\pm 7 \%$. The median European System for Cardiac Operative Risk Evaluation II was 5\% (interquartile range, 3\%-12\%). Nonelective surgery was performed in 29 patients $(21 \%)$. Echocardiographic assessment of RVFAC, TAPSE, and RV LPSS was feasible in 136 patients (98\%), 137 patients $(99 \%)$, 


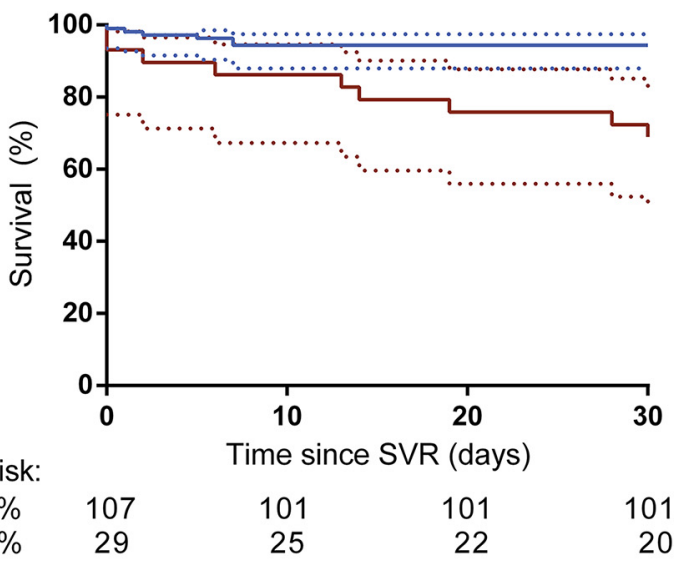

- RVFAC $\geq 35 \%$

- RVFAC $<35 \%$

$\mathrm{P}<0.01$

Numbers at risk:

RVFAC $\geq 35 \%$

29

25

22

101

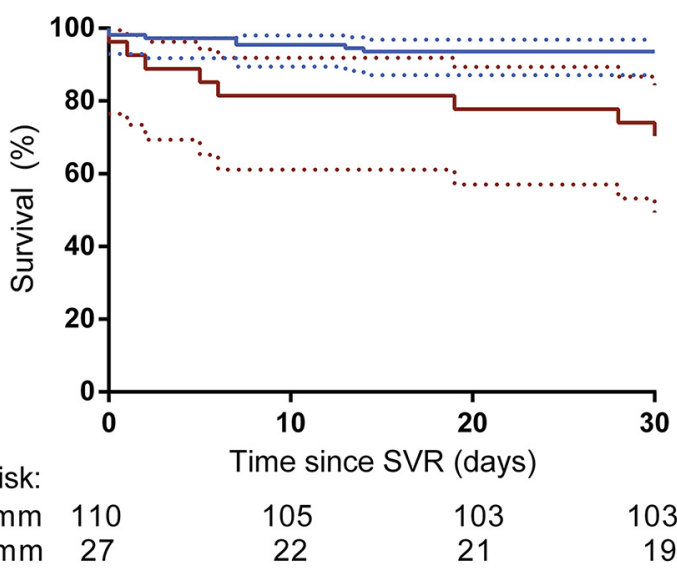

- TAPSE $\geq 16 \mathrm{~mm}$

- TAPSE $<16 \mathrm{~mm}$

$\mathrm{P}<0.01$

Numbers at risk:

TAPSE $\geq 16 \mathrm{~mm} \quad 110$

22

21

19

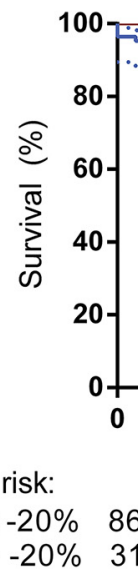

Numbers at risk:

$\begin{array}{ll}\text { RV LPSS } \leq-20 \% & 86 \\ \text { RV LPSS }>-20 \% & 31\end{array}$

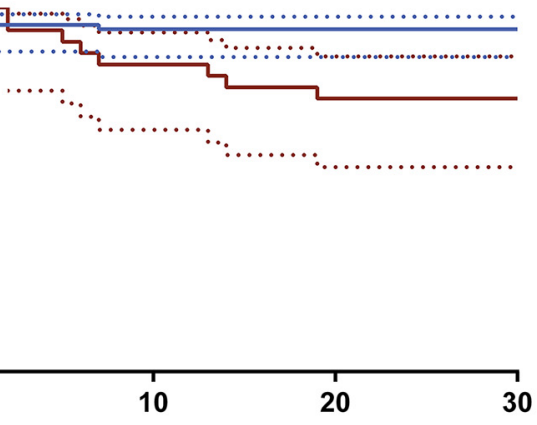

Time since SVR (days)

- RV LPSS $\leq-20 \%$

- RV LPSS $>-20 \%$

$P<0.01$

FIGURE 1. Kaplan-Meier survival curves for baseline normal versus impaired RV function in patients after SVR. A, RVFAC. B, TAPSE. C, RV LPSS. $R V F A C$, Right ventricular fractional area change; TAPSE, tricuspid annular plane systolic excursion; $R V L P S S$, right ventricular longitudinal peak systolic strain; SVR, surgical ventricular restoration. Dashed lines: $95 \%$ CI.

and 117 patients (84\%), respectively. Mean RVFAC was $42 \% \pm 9 \%$, mean TAPSE was $18 \pm 3 \mathrm{~mm}$, and mean RV LPSS was $-24 \% \pm 7 \%$. RVFAC was impaired in 29 patients $(21 \%)$, TAPSE was impaired in 27 patients $(20 \%)$, and RV LPSS was impaired in 31 patients (27\%). In 114 patients, all 3 measurements of RVFAC, TAPSE, and RV LPSS could be assessed. In this population, 44 patients
$(39 \%)$ had 1 or more parameters of impaired RV function. Bland-Altman analysis showed good intraobserver and interobserver agreement. Mean differences were $0.41 \pm 2.66$ for RVFAC, $0.25 \pm 1.29$ for TAPSE, and $0.07 \pm 2.28$ for RV LPSS for interobserver variability and $0.60 \pm 2.78$ for RVFAC, $0.05 \pm 0.69$ for TAPSE, and $0.10 \pm 1.48$ for RV LPSS for intraobserver variability. 
TABLE 2. Multivariable Cox regression analysis of 30-day mortality and right ventricular function: Correlates of 30-day mortality including RVFAC, TAPSE, and RV LPSS

\begin{tabular}{|c|c|c|c|c|c|c|}
\hline & \multicolumn{3}{|c|}{ Univariable analysis } & \multicolumn{3}{|c|}{ Multivariable analysis } \\
\hline & HR & $\mathbf{9 5} \% \mathrm{CI}$ & $P$ value & HR & $\mathbf{9 5} \% \mathbf{C I}$ & $P$ value \\
\hline \multicolumn{7}{|l|}{ RVFAC } \\
\hline $\operatorname{LVEF}(\%)$ & 0.93 & $0.87-0.99$ & .03 & 0.91 & $0.84-0.99$ & .03 \\
\hline Aortic crossclamping time (min) & 1.01 & $1.00-1.01$ & $<.01$ & 1.01 & $1.0-1.01$ & $<.01$ \\
\hline RVFAC & 0.92 & $0.88-0.97$ & $<.01$ & 0.93 & $0.88-0.98$ & $<.01$ \\
\hline \multicolumn{7}{|l|}{ TAPSE } \\
\hline LVEF $(\%)$ & 0.93 & $0.87-0.99$ & .03 & 0.94 & $0.86-1.02$ & .12 \\
\hline Aortic crossclamping time (min) & 1.01 & $1.00-1.01$ & $<.01$ & 1.01 & $1.0-1.01$ & $<.01$ \\
\hline TAPSE & 0.78 & $0.65-0.94$ & $<.01$ & 0.80 & $0.66-0.96$ & .02 \\
\hline \multicolumn{7}{|l|}{ RV LPSS } \\
\hline LVEF $(\%)$ & 0.93 & $0.87-0.99$ & .03 & 0.95 & $0.87-1.03$ & .17 \\
\hline Aortic crossclamping time (min) & 1.01 & $1.00-1.01$ & $<.01$ & 1.01 & $1.0-1.01$ & $<.01$ \\
\hline RV LPSS & 1.14 & $1.04-1.24$ & .01 & 1.15 & $1.05-1.26$ & $<.01$ \\
\hline
\end{tabular}

Bold signifies statistical significance. $H R$, Hazard ratio; $C I$, confidence interval; $R V F A C$, right ventricular fractional area change; $L V E F$, left ventricular ejection fraction; $T A P S E$, tricuspid annular plane systolic excursion; RV LPSS, right ventricular longitudinal peak systolic strain.

\section{Surgical Data and Postoperative Survival}

At the time of SVR, concomitant CABG, mitral valve surgery, and tricuspid valve surgery were performed in 74 patients $(53 \%), 73$ patients $(53 \%)$, and 36 patients $(26 \%)$, respectively. Ablation for ventricular tachycardias was performed in 58 patients $(42 \%)$ and included endocardial resection in 11 patients $(8 \%)$. Mean aortic crossclamping time was $148 \pm 69$ minutes. Within 30 days after surgery, 15 patients died, yielding a survival of $89 \%$. All 15 deaths within the first 30 days were heart failure related, and 10 of 15 patients $(67 \%)$ clinically experienced postoperative RV failure. In 8 of 15 patients (53\%), mechanical support (intra-aortic balloon pump or extracorporeal membrane oxygenation) was used postoperatively to attempt to support cardiac function.

\section{Associates of 30-Day Survival}

Univariable Cox regression analysis revealed that the European System for Cardiac Operative Risk Evaluation II, nonelective surgery, aortic crossclamping time, CABG, LVEF, RVFAC, TAPSE, and RV LPSS were associated with 30-day mortality (Table 1). As shown in Figure 1, the 30-day survivals of patients dichotomized on the basis of RVFAC $35 \%$ or more or less than $35 \%$ were $94 \%$ and $69 \%$, respectively $(P<.01)$. Likewise, at 30 -day followup, higher survival was observed in patients with TAPSE $16 \mathrm{~mm}$ or greater compared with patients with TAPSE less than $16 \mathrm{~mm}(94 \%$ vs $70 \%, P<.01)$ and in patients with RV LPSS $-20 \%$ or less compared with patients with RV LPSS greater than $-20 \%(94 \%$ vs $74 \%, P<.01)$. Multivariable Cox regression analysis was performed to assess the association between each separate continuous parameter of RV function and 30-day mortality, adjusted for LVEF and aortic crossclamping time. As shown in Table 2, the multivariable analysis revealed that RVFAC
(HR, 0.93; 95\% CI, 0.88-0.98; $P<.01$ ), TAPSE (HR, $0.80 ; 95 \%$ CI, 0.66-0.96; $P=.02$ ), and RV LPPS (HR, $1.15 ; 95 \% \mathrm{CI}, 1.05-1.26 ; P<.01)$ remained independently associated with 30-day mortality, after adjusting for LVEF and aortic crossclamping time. Subsequently, the additive effect of multiple impaired RV parameters on mortality was investigated. The 30 -day survival was $97 \%$ in patients with no echocardiographic parameters of impaired RV function, $83 \%$ in patients with 1 impaired parameter, $73 \%$ in patients with 2 impaired parameters, and $40 \%$ in patients with 3 parameters of impaired RV function $(P<.01)$, as shown in Figure 2. On multivariable Cox regression analysis, the coexistence of several impaired $\mathrm{RV}$ parameters per patient remained independently associated with increased 30-day mortality (HR, 2.83; 95\% CI, $1.64-4.87 ; P<.01$ per additional impaired parameter) after adjusting for LVEF and aortic crossclamping time. The results are also presented in Video 1.

\section{DISCUSSION}

The main finding of the current study is that preoperative $\mathrm{RV}$ dysfunction was an important determinant of postoperative survival in patients with ischemic heart failure undergoing SVR. In particular, reduced RVFAC, TAPSE, and RV LPSS as assessed by echocardiography were independently associated with increased 30-day mortality. Furthermore, a higher number of impaired RV parameters per patient was associated with increased mortality.

Impaired RV function, as assessed with a wide variety of parameters, is a well-known risk factor for mortality in the general population with heart failure. ${ }^{15-20}$ Previous studies also demonstrated that RV function is a prognostic marker in patients with heart failure undergoing cardiac surgery. Maslow and colleagues ${ }^{21}$ showed that baseline RV dysfunction was associated with poor outcome in patients with 


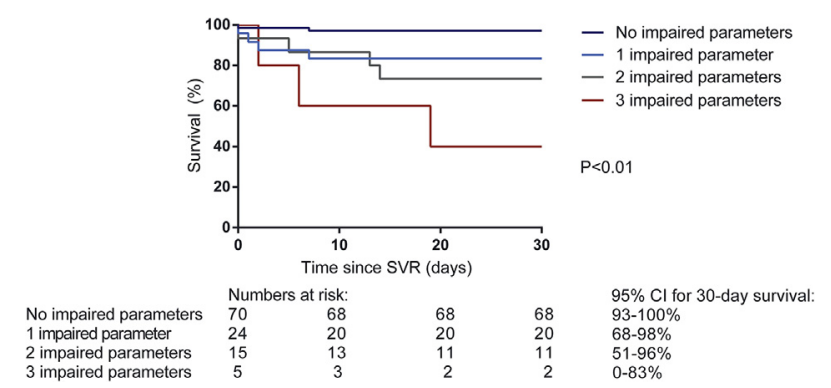

FIGURE 2. Kaplan-Meier survival curves for the coexistence of multiple parameters of impaired RV function in patients after SVR. Patients with no, 1,2 , and 3 parameters of impaired RV function. SVR, Surgical ventricular restoration. Dashed lines: 95\% CI.

severe LV dysfunction undergoing CABG. Furthermore, Dandel and colleagues ${ }^{22}$ showed an association between preoperative RV function and outcome in patients undergoing LV assist device (LVAD) implantation and emphasized the additive value of combining RV parameters to quantify RV function.

Conceptually, RV function also may be an important prognostic determinant after SVR. Previous studies reported that SVR enhances LV systolic function but also can impair LV diastolic properties, resulting in elevation of LV filling pressures and increased RV afterload. ${ }^{23-25}$ Furthermore, the more spherical LV geometry after SVR alters the position and function of the interventricular septum, which may influence RV geometry and function. ${ }^{26,27}$ Therefore, preoperative assessment of RV function seems to be an important variable to consider in patient selection for SVR.

Data associating RV function and outcome in patients with ischemic heart failure undergoing SVR are scarce. Kukulski and colleagues ${ }^{5}$ examined the prevalence of RV dysfunction and its effect on outcome in a subgroup of

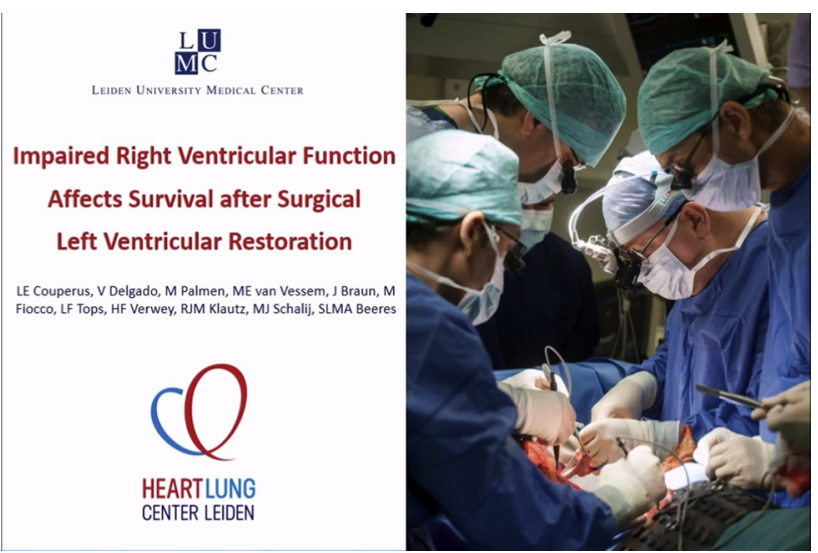

VIDEO 1. RV dysfunction affects survival after SVR. Description of the methods and main outcomes of the present study, including details on the echocardiographic measurements and surgical procedure. Video available at: http://www.jtcvsonline.org/article/S0022-5223(16)31156-4/addons.
866 patients included in the Surgical Treatment for Ischemic Heart Failure trial. RV dysfunction was visually assessed with echocardiography and classified as mild in $12 \%$ of patients and moderate to severe in $9 \%$ of patients. The grade of RV dysfunction was associated with advanced LV remodeling and worse hemodynamic profiles. Patients with moderate to severe RV dysfunction who received CABG and SVR had significantly higher mortality and cardiovascular hospitalization rates at long-term follow-up compared with patients who received CABG alone. Kukulski and colleagues ${ }^{5}$ concluded that adding SVR to CABG may worsen survival in patients with moderate to severe RV dysfunction. However, it should be noted that visual classification of RV dysfunction is difficult to categorize and may be inaccurate and with poor interobserver agreement.

Furthermore, Garatti and colleagues ${ }^{6}$ assessed the relation between RV function and clinical outcome after SVR. A total of 324 patients underwent SVR, and concomitant CABG was performed in $90 \%$ of patients. RV dysfunction, defined as TAPSE less than $16 \mathrm{~mm}$, was present in $21 \%$ of patients and associated with a higher frequency of so-called low-output syndrome, postoperative inotropic support, and intra-aortic balloon pump insertion. In this study, no statistically significant difference in 30-day survival was found between patients with and without RV dysfunction, but 5- and 8-year survivals and freedom from cardiac events were significantly lower in patients with preoperative RV dysfunction. However, it has to be noted that TAPSE is only an approximate indicator of RV function that does not reflect the complex geometry and function of the right ventricle.

Similar to these studies, the present study confirmed the association between RV dysfunction and increased mortality after SVR. However, our data extend the insights into this association by adding the assessment of RV function based on myocardial strain. RV LPSS is a novel measurement that assesses free wall deformation independently of the angle of the ultrasound beam. ${ }^{9,28}$ In addition, the use of standardized measuring techniques and generally acknowledged cutoff values make our findings easily reproducible for future patients considered for SVR. ${ }^{9,11}$ Comprehensive echocardiographic assessment of multiple $\mathrm{RV}$ functional parameters revealed a higher proportion of patients with any sign of RV dysfunction compared with previous studies $39 \% \mathrm{RV}$ dysfunction in the present study vs $21 \%$ in studies by Kukulski and colleagues ${ }^{5}$ and Garatti and colleagues ${ }^{6}$ ). Our findings demonstrate for the first time that a higher number of impaired RV parameters per patient had an incremental worse effect on 30-day survival. Furthermore, Kukulski and colleagues ${ }^{5}$ showed that RV dysfunction was associated with advanced LV remodeling and proposed that the negative effect of RV dysfunction on outcome after SVR was dependent on this association. 
The present study is the first to demonstrate that impaired $\mathrm{RV}$ function is an independent marker for worse survival in patients undergoing SVR, after adjusting for LVEF. Consequently, the current study increases knowledge on the diagnosis and implications of RV impairment in patients undergoing SVR.

\section{Study Limitations}

First, echocardiographic evaluation of the right ventricle is subject to adequate visualization of its complex 3-dimensional geometry and dependent on the RV preload and afterload. ${ }^{22,29}$ Furthermore, because of the retrospective nature of this study, no information is available regarding patients rejected for SVR. Therefore, comparison on survival between operated and nonoperated patients with $\mathrm{RV}$ dysfunction could not be performed.

\section{Clinical Implications}

The current study emphasizes the importance of patient selection for SVR, because postoperative mortality is significantly increased in patients with preexistent RV dysfunction. Comprehensive echocardiography using multiple measuring techniques is essential to characterize overall RV function. Patients with RV dysfunction could benefit from additional perioperative measures for RV protection, such as the use of inhaled nitric oxide. Otherwise, refraining from SVR should be considered carefully in patients at increased risk for postoperative RV failure. Apart from heart transplant, an alternative treatment option in those patients might even be LVAD implantation because previous studies showed that mechanical unloading of the LV decreases LV filling pressures and thereby reduces RV afterload. ${ }^{30,31}$ Nonetheless, it has to be noted that LVAD implantation brings its own challenges to RV function. ${ }^{22,32}$

\section{CONCLUSIONS}

Preexistent RV dysfunction in patients with ischemic heart failure undergoing SVR is frequent and associated with increased postoperative mortality. Comprehensive preoperative echocardiography is essential to characterize RV function and can optimize patient selection for SVR.

\section{Conflict of Interest Statement}

The Department of Cardiology receives unrestricted grants from Biotronik (Berlin, Germany), Boston Scientific (Marlborough, Mass), and Medtronic (Minneapolis, Minn). V.D. receives speaker fees from Abbott Vascular (Abbott Park, Ill). No sponsor participated in the design of the study, collecting, analyzing and interpreting of the data, writing the report, or deciding to submit the report for publication. All other authors have nothing to disclose with regard to commercial support.

\section{References}

1. Michler RE, Rouleau JL, Al-Khalidi HR, Bonow RO, Pellikka PA, Pohost GM, et al; STICH Trial Investigators. Insights from the STICH trial: change in left ventricular size after coronary artery bypass grafting with and without surgical ventricular reconstruction. J Thorac Cardiovasc Surg. 2013; 146:1139-45.e6

2. Athanasuleas CL, Buckberg GD, Stanley AW, Siler W, Dor V, DiDonato M, et al; RESTORE Group. Surgical ventricular restoration: the RESTORE Group experience. Heart Fail Rev. 2004;9:287-97.

3. Oh JK, Velazquez EJ, Menicanti L, Pohost GM, Bonow RO, Lin G, et al; STICH Investigators. Influence of baseline left ventricular function on the clinical outcome of surgical ventricular reconstruction in patients with ischaemic cardiomyopathy. Eur Heart J. 2013;34:39-47.

4. Witkowski TG, ten Brinke EA, Delgado V, Ng AC, Bertini M, Marsan NA, et al Surgical ventricular restoration for patients with ischemic heart failure: determinants of two-year survival. Ann Thorac Surg. 2011;91:491-8.

5. Kukulski T, She L, Racine N, Gradinac S, Panza JA, Velazquez EJ, et al; Surgical Treatment for Ischemic Heart Failure Investigators. Implication of right ventricular dysfunction on long-term outcome in patients with ischemic cardiomyopathy undergoing coronary artery bypass grafting with or without surgical ventricular reconstruction. J Thorac Cardiovasc Surg. 2015;149:1312-21.

6. Garatti A, Castelvecchio S, Di Mauro M, Bandera F, Guazzi M, Menicanti L. Impact of right ventricular dysfunction on the outcome of heart failure patients undergoing surgical ventricular reconstruction. Eur J Cardiothorac Surg. 2015;47:333-40

7. Dor V, Saab M, Coste P, Kornaszewska M, Montiglio F. Left ventricular aneurysm: a new surgical approach. Thorac Cardiovasc Surg. 1989;37:11-9.

8. Cockcroft DW, Gault MH. Prediction of creatinine clearance from serum creatinine. Nephron. 1976;16:31-41.

9. Lang RM, Badano LP, Mor-Avi V, Afilalo J, Armstrong A, Ernande L, et al. Recommendations for cardiac chamber quantification by echocardiography in adults: an update from the American Society of Echocardiography and the European Association of Cardiovascular Imaging. J Am Soc Echocardiogr. 2015;28: 1-39.e14.

10. Nagueh SF, Appleton CP, Gillebert TC, Marino PN, Oh JK, Smiseth OA, et al Recommendations for the evaluation of left ventricular diastolic function by echocardiography. Eur J Echocardiogr. 2009;10:165-93.

11. Rudski LG, Lai WW, Afilalo J, Hua L, Handschumacher MD, Chandrasekaran K et al. Guidelines for the echocardiographic assessment of the right heart in adults: a report from the American Society of Echocardiography endorsed by the European Association of Echocardiography, a registered branch of the European Society of Cardiology, and the Canadian Society of Echocardiography. J Am Soc Echocardiogr. 2010;23:685-713. quiz 86-8.

12. Joint Task Force on the Management of Valvular Heart Disease of the European Society of Cardiology, European Association for Cardiothoracic Surgery, Vahanian A, Alfieri O, Andreotti F, Antunes MJ, Barón-Esquivias G, Baumgartner H, et al. Guidelines on the management of valvular heart disease (version 2012). Eur Heart J. 2012;33:2451-96.

13. McMurray JJ, Adamopoulos S, Anker SD, Auricchio A, Bohm M, Dickstein K et al. ESC Guidelines for the diagnosis and treatment of acute and chronic heart failure 2012: The Task Force for the Diagnosis and Treatment of Acute and Chronic Heart Failure 2012 of the European Society of Cardiology. Developed in collaboration with the Heart Failure Association (HFA) of the ESC. Eur Heart J. 2012;33:1787-847.

14. Klein P, Holman ER, Versteegh MI, Boersma E, Verwey HF, Bax JJ, et al. Wall motion score index predicts mortality and functional result after surgical ventricular restoration for advanced ischemic heart failure. Eur J Cardiothorac Surg. 2009;35:847-53.

15. Meyer P, Filippatos GS, Ahmed MI, Iskandrian AE, Bittner V, Perry GJ, et al. Effects of right ventricular ejection fraction on outcomes in chronic systolic heart failure. Circulation. 2010;121:252-8.

16. Meluzin J, Spinarova L, Hude P, Krejci J, Kincl V, Panovsky R, et al. Prognostic importance of various echocardiographic right ventricular functional parameters in patients with symptomatic heart failure. J Am Soc Echocardiogr. 2005;18: 435-44.

17. de Groote P, Fertin M, Goeminne C, Petyt G, Peyrot S, Foucher-Hossein C, et al Right ventricular systolic function for risk stratification in patients with stable left ventricular systolic dysfunction: comparison of radionuclide angiography to echoDoppler parameters. Eur Heart J. 2012;33:2672-9.

18. Ghio S, Recusani F, Klersy C, Sebastiani R, Laudisa ML, Campana C, et al. Prognostic usefulness of the tricuspid annular plane systolic excursion in patients with 
congestive heart failure secondary to idiopathic or ischemic dilated cardiomyopathy. Am J Cardiol. 2000;85:837-42.

19. Dokainish H, Sengupta R, Patel R, Lakkis N. Usefulness of right ventricular tissue Doppler imaging to predict outcome in left ventricular heart failure independent of left ventricular diastolic function. Am J Cardiol. 2007;99:961-5.

20. Damy T, Viallet C, Lairez O, Deswarte G, Paulino A, Maison P, et al. Comparison of four right ventricular systolic echocardiographic parameters to predict adverse outcomes in chronic heart failure. Eur J Heart Fail. 2009;11:818-24.

21. Maslow AD, Regan MM, Panzica P, Heindel S, Mashikian J, Comunale ME. Precardiopulmonary bypass right ventricular function is associated with poor outcome after coronary artery bypass grafting in patients with severe left ventricular systolic dysfunction. Anesth Analg. 2002;95:1507-18. table of contents.

22. Dandel M, Potapov E, Krabatsch T, Stepanenko A, Low A, Vierecke J, et al. Load dependency of right ventricular performance is a major factor to be considered in decision making before ventricular assist device implantation. Circulation. 2013; 128(11 Suppl 1):S14-23.

23. Tulner SA, Bax JJ, Bleeker GB, Steendijk P, Klautz RJ, Holman ER, et al. Beneficial hemodynamic and clinical effects of surgical ventricular restoration in patients with ischemic dilated cardiomyopathy. Ann Thorac Surg. 2006;82:1721-7.

24. ten Brinke EA, Klautz RJ, Tulner SA, Verwey HF, Bax JJ, Schalij MJ, et al. Longterm effects of surgical ventricular restoration with additional restrictive mitral annuloplasty and/or coronary artery bypass grafting on left ventricular function: six-month follow-up by pressure-volume loops. J Thorac Cardiovasc Surg. 2010; 140:1338-44.

25. Di Donato M, Fantini F, Toso A, Castelvecchio S, Menicanti L, Annest L, et al. Impact of surgical ventricular reconstruction on stroke volume in patients with ischemic cardiomyopathy. J Thorac Cardiovasc Surg. 2010;140:1325-31.e1-2.

26. Cho Y, Ueda T, Inoue Y, Shimura S, Aki A, Furuya H, et al. Long-term results and mid-term features of left ventricular reconstruction procedures on left ventricular volume, geometry, function and mitral regurgitation. Eur J Cardiothorac Surg. 2012;42:462-9.

27. Di Donato M, Sabatier M, Dor V, Gensini GF, Toso A, Maioli M, et al. Effects of the Dor procedure on left ventricular dimension and shape and geometric correlates of mitral regurgitation one year after surgery. J Thorac Cardiovasc Surg. 2001:121:91-6.

28. Amundsen BH, Helle-Valle T, Edvardsen T, Torp H, Crosby J, Lyseggen E, et al Noninvasive myocardial strain measurement by speckle tracking echocardiography: validation against sonomicrometry and tagged magnetic resonance imaging J Am Coll Cardiol. 2006;47:789-93.

29. Garcia Gigorro R, Renes Carreno E, Mayordomo S, Marin H, Perez Vela JL, Corres Peiretti MA, et al. Evaluation of right ventricular function after car diac surgery: the importance of tricuspid annular plane systolic excursion and right ventricular ejection fraction. J Thorac Cardiovasc Surg. 2016; 152:613-20.

30. Atluri P, Fairman AS, MacArthur JW, Goldstone AB, Cohen JE, Howard JL, et al Continuous flow left ventricular assist device implant significantly improves pulmonary hypertension, right ventricular contractility, and tricuspid valve competence. J Card Surg. 2013;28:770-5.

31. Mikus E, Stepanenko A, Krabatsch T, Loforte A, Dandel M, Lehmkuhl HB, et al Reversibility of fixed pulmonary hypertension in left ventricular assist device support recipients. Eur J Cardiothorac Surg. 2011;40:971-7.

32. Gaffey AC, Atluri P. Post-left ventricular assist device support right ventricular failure: Can it be predicted preoperatively, and should it be a contraindication to implantation? J Thorac Cardiovasc Surg. 2015;150:1659-60.

Key Words: heart failure, right ventricular function, surgical left ventricular restoration

Readers who found these articles interesting may also like to read the following papers found in recent and future issues of our sister publications, Seminars in Thoracic and Cardiovascular Surgery and Operative Techniques in Thoracic and Cardiovascular Surgery!

\section{Acquired: Coronary Artery Disease}

Open Aortic Arch Reconstruction After Coronary Artery Bypass Surgery: Worth the Effort? Eduard Quintana. Semin Thoracic Surg 2016:26-35

Risky Business or Acceptable Risk? Open Arch Repair After Coronary Artery Bypass Surgery. Joseph S. Coselli. Semin Thoracic Surg 2016:36-37

Off-Pump Coronary Artery Bypass Grafting Bobby Yanagawa. Oper Tech Thorac Cardiovasc 2016:2-18

Total Arterial Revascularization Silvana Marasco. Oper Tech Thorac Cardiovasc 2016:19-29 